\title{
Synchronous Inhibitory Potentials Precede Seizure-Like Events in Acute Models of Focal Limbic Seizures
}

\author{
Laura Uva, ${ }^{1 \star}$ Gian Luca Breschi, ${ }^{2 *}$ Vadym Gnatkovsky, ${ }^{1}$ Stefano Taverna, ${ }^{2}$ and Marco de Curtis ${ }^{1}$ \\ ${ }^{1}$ Unit of Epileptology and Experimental Neurophysiology, Fondazione Istituto Neurologico Carlo Besta, 20133 Milano, Italy, and ${ }^{2}$ Department of \\ Neuroscience and Brain Technologies, Italian Institute of Technology, 16163 Genova, Italy
}

Interictal spikes in models of focal seizures and epilepsies are sustained by the synchronous activation of glutamatergic and GABAergic networks. The nature of population spikes associated with seizure initiation (pre-ictal spikes; PSs) is still undetermined. We analyzed the networks involved in the generation of both interictal and PSs in acute models of limbic cortex ictogenesis induced by pharmacological manipulations. Simultaneous extracellular and intracellular recordings from both principal cells and interneurons were performed in the medial entorhinal cortex of the in vitro isolated guinea pig brain during focal interictal and ictal discharges induced in the limbic network by intracortical and brief arterial infusions of either bicuculline methiodide (BMI) or 4-aminopyridine (4AP). Local application of BMI in the entorhinal cortex did not induce seizure-like events (SLEs), but did generate periodic interictal spikes sensitive to the glutamatergic non-NMDA receptor antagonist DNQX. Unlike local applications, arterial perfusion of either BMI or 4AP induced focal limbic SLEs. PSs just ahead of SLE were associated with hyperpolarizing potentials coupled with a complete blockade of firing in principal cells and burst discharges in putative interneurons. Interictal population spikes recorded from principal neurons between two SLEs correlated with a depolarizing potential. We demonstrate in two models of acute limbic SLE that PS events are different from interictal spikes and are sustained by synchronous activation of inhibitory networks. Our findings support a prominent role of synchronous network inhibition in the initiation of a focal seizure.

Key words: acute seizure model; entorhinal cortex; focal seizures; in vitro guinea pig brain; interictal spikes; pre-ictal spikes

\section{Introduction}

Epileptiform interictal spikes (ISs) in models of focal seizures and of chronic epilepsy correlate with an intracellular pattern defined as paroxysmal depolarizing shift (PDS; Matsumoto and AjmoneMarsan, 1964), which is characterized by a sequence of fast action potentials superimposed to a slow depolarization (de Curtis and Avanzini, 2001). In limbic and olfactory cortices, ISs induced by pharmacological manipulations are sustained by the activation of synchronous glutamatergic networks (Hoffman and Haberly, 1991; de Curtis et al., 1999; Avoli et al., 2002). In the presence of glutamate receptor antagonists, $\mathrm{GABA}_{\mathrm{A}}$-receptor-mediated ISs have been observed in in vitro models of seizure-like events (SLEs) induced by applications of 4-aminopyridine (4AP; Michelson and Wong, 1991; Perreault and Avoli, 1992; Uva et al., 2009), carbachol (Dickson and Alonso, 1997), and GABA B $_{\text {recep- }}$ tor antagonists (Uusisaari et al., 2002). Moreover, the $\mathrm{GABA}_{\mathrm{A}}$ receptor antagonist bicuculline abolished spontaneous ISs re-

Received Sept. 4, 2014; revised Nov. 12, 2014; accepted Dec. 1, 2014.

Author contributions: L.U., G.L.B., V.G., S.T., and M.d.C. designed research; L.U., G.L.B., and V.G. performed research; L.U., G.L.B., V.G., S.T., and M.d.C. analyzed data; L.U., G.L.B., S.T., and M.d.C. wrote the paper.

This work was supported by the Italian Health Ministry (Grant Giovani Ricercatori RF 114, Ricerca Corrente) and by Telethon (Grants GGP07278 and GGP 12265).

The authors declare no competing financial interests.

*L.U. and G.L.B. contributed equally to this work.

Correspondence should be addressed to Marco de Curtis, Unit of Epileptology and Experimental Neurophysiology, Fondazione Istituto Neurologico, 20133 Milano, Italy. E-mail: decurtis@istituto-besta.it.

DOI:10.1523/JNEUROSCI.3692-14.2015

Copyright $\odot 2015$ the authors $\quad 0270-6474 / 15 / 353048-08 \$ 15.00 / 0$ corded on postsurgical, in vitro brain slices of subiculum and in CA2 hippocampal regions obtained from patients with focal drug-resistant temporal lobe epilepsy (Huberfeld et al., 2007; Wittner et al., 2009). These data demonstrate that both glutamatergic and GABAergic networks can independently sustain epileptiform spikes in different experimental conditions.

The involvement of inhibitory networks at seizure onset is supported by experimental and clinical evidence (de Curtis and Gnatkovsky, 2009; Avoli and de Curtis, 2011). Inhibitory neuron discharges during the transition into a focal seizure were demonstrated in experimental studies performed on in vitro models of SLEs (Avoli, 1990, 1996; Lopantsev and Avoli, 1998; Derchansky et al., 2008; Ziburkus et al., 2006; Gnatkovsky et al., 2008; Lasztoczi et al., 2009; Fujiwara-Tsukamoto et al., 2010). GABA $_{\mathrm{A}^{-}}$ mediated synchronization promotes SLEs in postsurgical slices obtained from patients with focal cortical dysplasia treated with 4AP (D'Antuono et al., 2004). In vivo unit recordings in a model of temporal lobe epilepsy demonstrated that principal neurons reduce their firing at the beginning of a seizure whereas interneuron activity increases (Grasse et al., 2013). A reduction of principal neurons firing suggestive of an inhibitory activity during the transition into seizure was also demonstrated with unit recordings performed in the course of presurgical monitoring with intracerebral microelectrodes in patients candidate to epilepsy surgery (Truccolo et al., 2011; Schevon et al., 2012).

The hypothesis that inhibitory network activation sustains seizure onset via the generation of pre-ictal spikes (PSs) is verified 
A
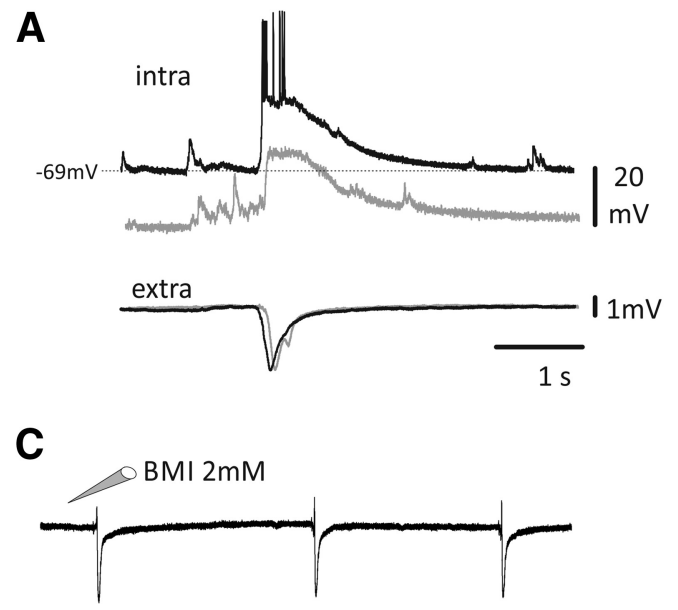

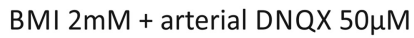

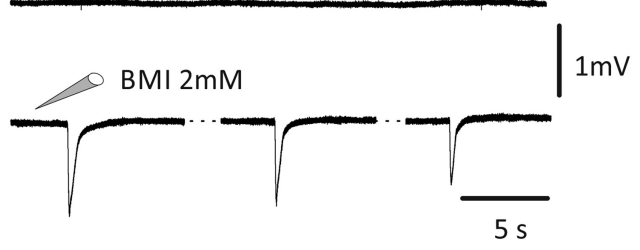

B

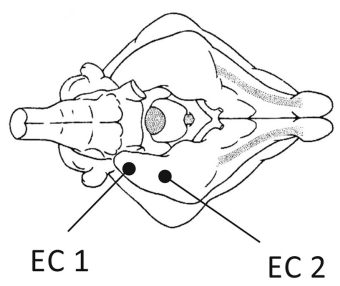

EC 1

$1 \mathrm{mV}$

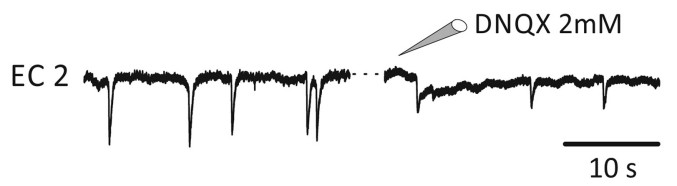

Figure 1. Local application of BMI (1-2 mM) in EC induced glutamatergic spikes. $A$, Example of ISs recorded in EC after local injection of BMI (bottom traces) and its intracellular correlate (top traces) showing the depolarization and firing of the cell at rest (black trace; resting membrane potential: $-69 \mathrm{mV}$ ) blocked by hyperpolarizing current injection (gray traces). $\boldsymbol{B}$, Top, Schematic drawing of the isolated guinea pig brain showing the position of the injecting-pipette-recording electrodes in the EC. As shown at the bottom, ISS were induced in both EC 1 and EC 2 by local application of BMI in EC 1. In EC 2, a decrease in amplitude of the spikes was observed after application of the non-NMDA glutamate receptor blocker DNQX ( $2 \mathrm{~mm})$. The difference between EC 1 and EC 2 spike amplitude was statistically significant ( $t$ test; $p=2.3 \mathrm{E}-7$; DF $=8.80$ ). C, Top, Local injection of BMI-induced ISs. Middle. When $50 \mu \mathrm{m}$ DNQX was arterially perfused for 45 min, local injection of BMI failed in generating ISs. Bottom, After 90 min washout, BMI local injection was successful in inducing ISS.

here during SLEs induced by two different pharmacological manipulations in the isolated guinea pig brain maintained in vitro. The network determinants of ictogenesis in the limbic region of this close-to-in vivo preparation have been studied extensively (de Curtis et al., 1994; Uva et al., 2005; Gnatkovsky et al., 2008; Trombin et al., 2011; Boido et al., 2014).

\section{Materials and Methods}

Brains of adult female Hartley guinea pigs (150-200 g; Charles River) were isolated and maintained in vitro according to the standard procedure described previously (de Curtis et al., 1991; Mühlethaler et al., 1993; de Curtis et al., 1998b). Briefly, the animals were anesthetized with sodium thiopental (125 mg/kg, i.p., Farmotal; Pharmacia) and were transcardially perfused with a cold $\left(10^{\circ} \mathrm{C}\right)$, carboxygenated $\left(95 \% \mathrm{O}_{2} / 5 \%\right.$ $\mathrm{CO}_{2}$ ) solution containing the following (in $\mathrm{mm}$ ): $126 \mathrm{NaCl}, 3 \mathrm{KCl}, 1.2$ $\mathrm{KH}_{2} \mathrm{PO}_{4}, 1.3 \mathrm{MgSO}_{4}, 2.4 \mathrm{CaCl}_{2}, 26 \mathrm{NaHCO}_{3}, 15$ glucose, and $2.1 \mathrm{HEPES}$ and $3 \%$ dextran molecular weight $70,000, \mathrm{pH}$ adjusted at 7.1 with $\mathrm{HCl}$. After decapitation, brains were isolated and transferred into a recording chamber. A cannula was inserted in the basilar artery and brain perfusion with the solution mentioned above $\left(7 \mathrm{ml} / \mathrm{min}, \mathrm{pH} 7.3,15^{\circ} \mathrm{C}\right)$ was restored via a peristaltic pump (Minipulse 3; Gilson). Before starting the electrophysiological experiment, the temperature of both the perfusate and the chamber was slowly $\left(0.2^{\circ} \mathrm{C} / \mathrm{min}\right)$ raised to $32^{\circ} \mathrm{C}$ by a temperature controller (PTC 10; NPI).

Extracellular recordings were performed in the medial entorhinal cortex (EC) using $0.9 \mathrm{M} \mathrm{NaCl}$-filled glass pipettes (5-10 $\mathrm{M} \Omega$ resistance) at $300-500 \mu \mathrm{m}$ in depth. EC responses evoked by electrical stimulation of the lateral olfactory tract (LOT) through an isolation unit driven by a pulse generator (Telefactor S88; Grass Instruments) were used to monitor the viability of the preparation during the experiment (Biella and de Curtis, 2000). Field potential signals were amplified with a multichannel differential amplifier (Biomedical Engineering) in quasi-DC mode ( 0.05 $\mathrm{Hz}$ high-pass filter). Intracellular recordings in the $\mathrm{EC}$ were performed with sharp glass micropipette containing $2 \mathrm{M}$ potassium acetate (input resistance: 60-120 M $\Omega$ ). Signals recorded with an intracellular bridge amplifier (Neuro Data Instruments) were digitized via an AT-MIO64E3 National A/D Board (National Instruments) and analyzed with custom-made software (ELPHO) developed in Labview by Dr. Vadym Gnatkovsky.

Epileptiform activities were induced by: (1) local intracortical application of the $\mathrm{GABA}_{\mathrm{A}}$ receptor antagonist bicuculline methiodide (BMI; Tocris Bioscience; $1-2 \mathrm{~mm}$ in $0.9 \mathrm{M}$ sodium chloride) in the EC through an injection pipette (tip diameter $10 \mu \mathrm{m}$ ) connected to a pulse-delivery controlled system (Picospritzer II; Parker Instrumentation); (2) brief arterial application of BMI (50 $\mu \mathrm{M} ; 3$ min perfusions); and (3) arterial application of the $\mathrm{K}^{+}$channel blocker, 4AP (50 $\mu \mathrm{M}$; 4 min perfusions; Fluka). Local intracortical application of the non-NMDA receptors antagonist DNQX (2 mM; Abcam) was performed using a Picospritzer.

Two-sample $t$ test was implemented to evaluate the effect of local DNQX application on BMI-induced spikes in 2 portions of EC $>2$ $\mathrm{mm}$ apart. For each test, after DNQX injection, the amplitude of the spikes was measured at the site of BMI injection (EC 1) and at the site of local DNQX injection (EC 2), the mean of the EC 1 and EC 2 spike amplitudes was calculated for each test $(n=9)$ and the $t$ test was performed comparing the means of EC 1 and EC 2 obtained from 5 to 10 couples of spikes for each test. Arterial applications of DNQX were performed dissolving DNQX in the perfusate $(50 \mu \mathrm{M})$ and the efficacy of the DNQX block was verified by evaluating the LOT-evoked response.

The number of animals used for the study was minimized according to the international guidelines on ethical use of animals [European Communities Council Directive of 24 November 1986 (86/109/EEC)]. The experimental protocol was reviewed and approved by the Committee on Animal Care and Use and by the Ethics Committee of the Fondazione Istituto Neurologico. 
A

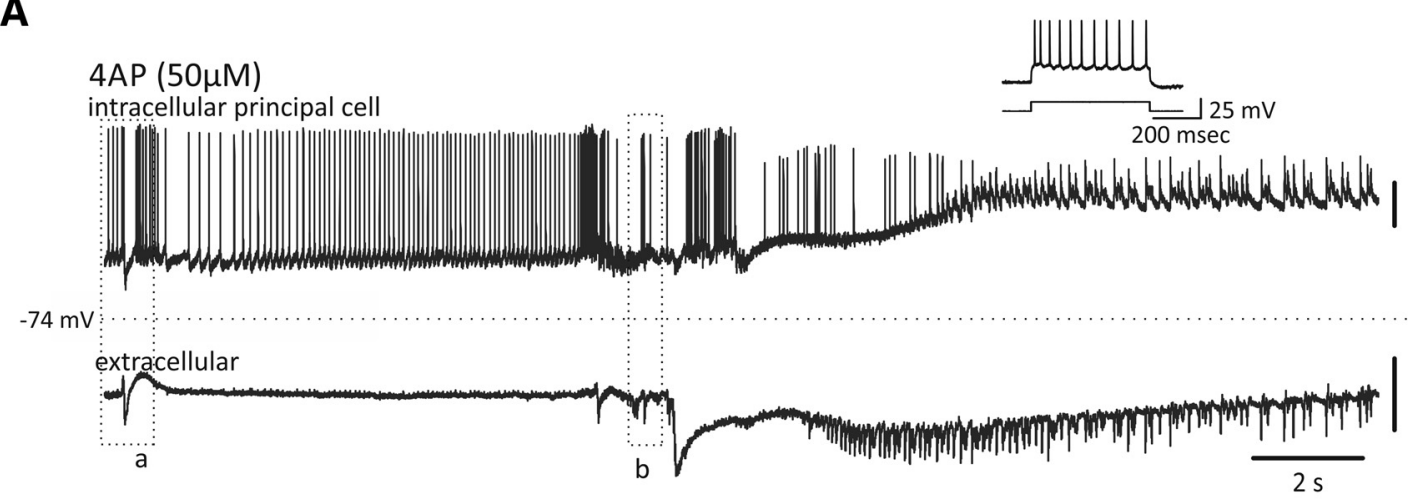

B LOT-evoked

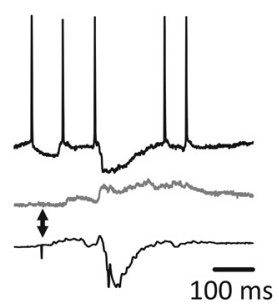

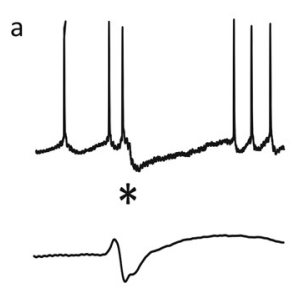

D

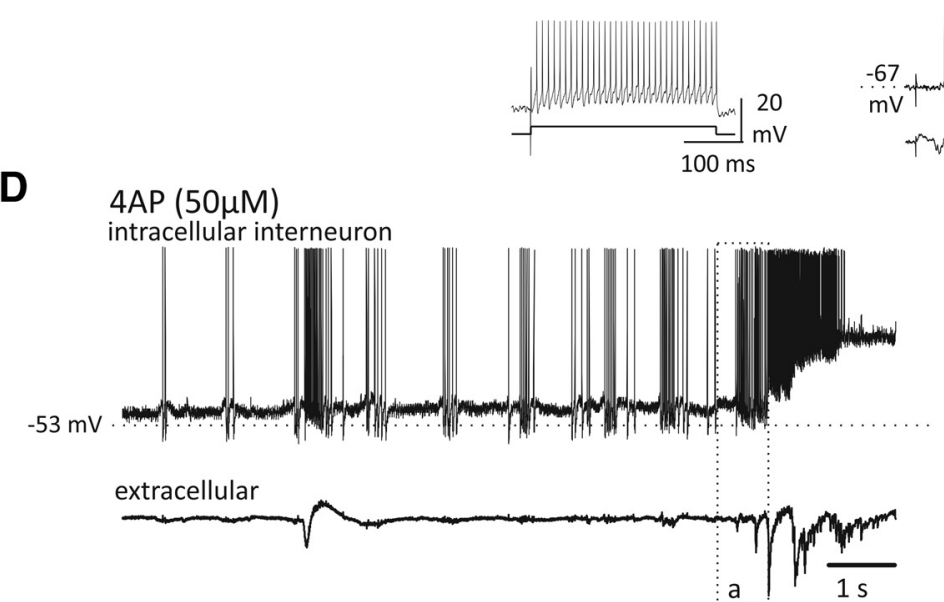

C
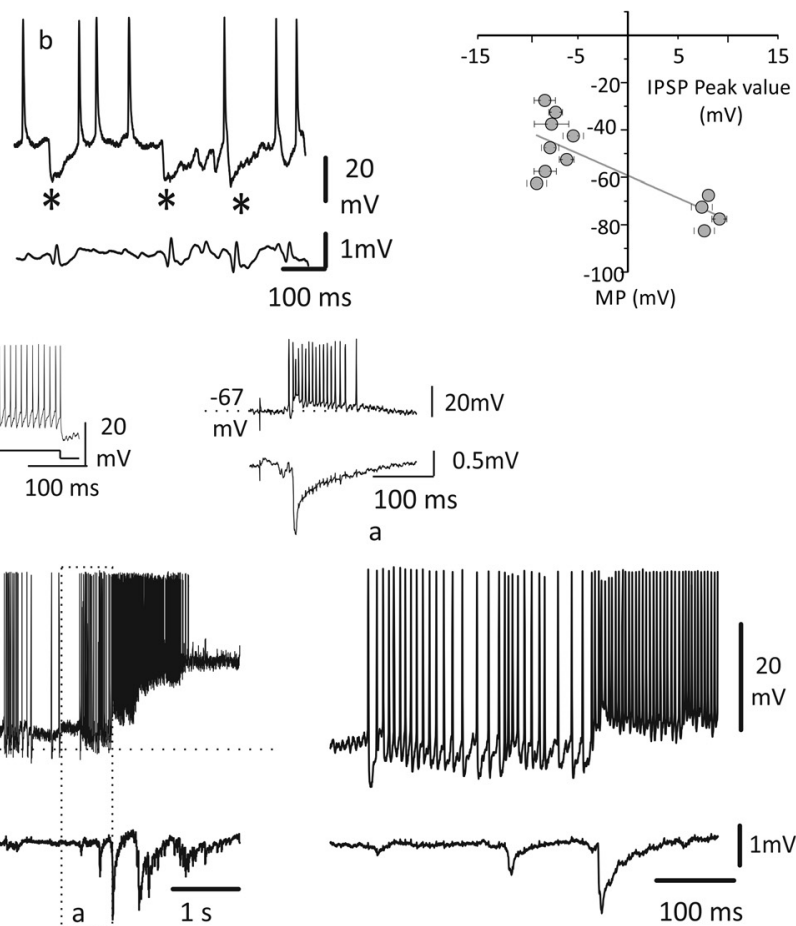

Figure 2. Transition to ictal discharge in EC principal neurons and interneurons. Arterial application of proconvulsant compounds induces PSs and ictal activity in EC. $\boldsymbol{A}$, Top, intracellular and extracellular activities during PSs and SLE onset induced by arterial application of (4AP; $50 \mu \mathrm{m} ; 4 \mathrm{~min}$ ). The cell membrane was artificially depolarized at $-40 \mathrm{mV}$ ( $\mathrm{rmp}:-74 \mathrm{mV}$ ). B, Example of two PSs $\left(^{*}\right)$ that correlate with membrane potential hyperpolarization. Left, Intracellular LOT-evoked potentials recorded at different cell membrane levels (top) demonstrate the presence of an IPSP with a reversal peak potential similar to the hyperpolarizing potential associated to PSs observed in $\boldsymbol{A}$ and $\boldsymbol{B}$ (in the middle and right, see also Gnatkovsky et al., 2006). The corresponding field potential is shown below each trace. C, Average IPSP amplitudes measured at different membrane potentials (MP) are plotted in the diagram. The $E_{\mathrm{REV}}-59.3 \pm 3.4 \mathrm{mV}$ ( $n=11$ cells) is extrapolated from the point where the gray line intersects the $y$-axis (mean \pm SD). $\boldsymbol{D}$, Left, Top, Intracellular activity of a putative interneuron and correlated extracellular activity (bottom traces) after arterial application of $4 A P(50 \mu \mathrm{m} ; 4 \mathrm{~min})$. Right, Activity recorded at the seizure onset is enlarged to show the intense discharge of the interneuron ( $\mathrm{rmp}$ : $-53 \mathrm{mV}$ ). Left, Typical high-frequency firing during depolarizing pulse is illustrated. Right insert, Typical interneuron bursting response to LOT stimulation is shown (see also Gnatkovsky et al., 2007).

\section{Results}

Local injections of BMI $(1-2 \mathrm{mM})$ in the EC $(n=33)$ generated ISs (Fig. 1) lasting $1128 \pm 413 \mathrm{~ms}$ (mean \pm SD) and recurring at $0.05-0.2 \mathrm{~Hz}$. The periodic IS pattern observed during local BMI application never evolved into SLEs. Intracellular recordings demonstrated that the ISs induced by local BMI corresponded to a depolarizing potential superimposed to a burst of spikes $(n=$ 21 ); action potential firing was abolished by intracellular injection of negative current that enhanced the amplitude of the underlying depolarizing potential $(n=7$; Fig. $1 A)$. Local EC injection of 2 mM DNQX (site EC 2 in Fig. $1 B$ ) determined a statistically significant decrease in IS amplitude (amplitude de- crease to $73.6 \pm 26.4 \%$ ) compared with EC regions remote to DNQX application where an increase of the ISs amplitude was observed (amplitude increase to $127.4 \pm 20.4 \% ; n=9 ; 2$-sample $t$ test, $p$-values for all tests were $<0.005)$. The complete abolition of the recorded spikes was not achieved in EC 2 because of the small area of action of DNQX compared with the whole extension of the EC. BMI-induced ISs were completely abolished by arterial application of $50 \mu \mathrm{M}$ DNQX $(n=4$; Fig. $1 C)$ and recovered by $90 \mathrm{~min}$ of washout repeating local BMI injections (Fig. $1 C$, bottom trace). These data suggest that activation of the excitatory glutamatergic circuit is required for the generation of ISs induced by local BMI injection in the EC. 


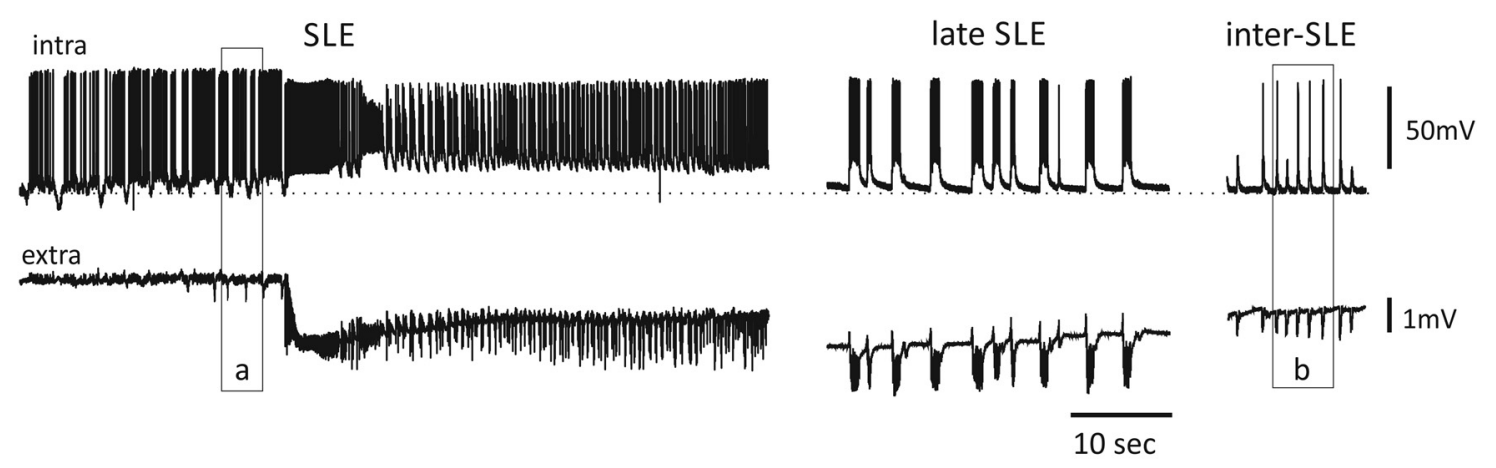

a
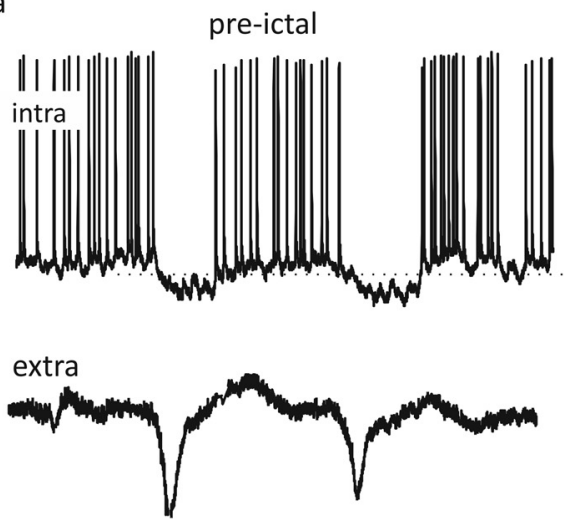

b
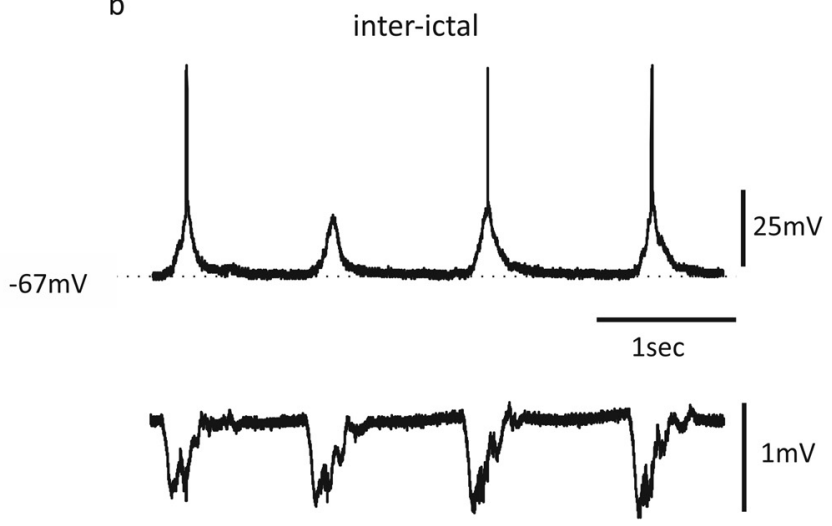

Figure 3. Simultaneous intracellular (top) and extracellular (bottom) recordings performed during a SLE (left and middle) and between two SLEs (right panel) induced by arterial perfusion of 50 $\mu \mathrm{m}$ BMI. In the middle panel, the bursting activity observed during the late phase of the SLE is shown. In the bottom panels, the correlates of PSs (a) and interictal spikes (b) are illustrated as expanded traces (in the outlined boxes).

When BMI $(50 \mu \mathrm{M})$ was arterially perfused for $3 \mathrm{~min}$ in the isolated guinea pig brain, population spikes transiently appeared in EC (Uva et al., 2005; Gnatkovsky et al., 2008; data not shown) and preceded the generation of SLEs (Librizzi and de Curtis, 2003). As demonstrated previously, brief application of $50 \mu \mathrm{M}$ BMI causes a reduction of $\mathrm{GABA}_{\mathrm{A}}$ transmission of $\sim 30 \%$, thus leaving the $\mathrm{GABA}_{\mathrm{A}}$ system partially operative (Gnatkovsky et al., 2008). As for BMI, arterial perfusion of $50 \mu \mathrm{M} 4 \mathrm{AP}$ induced SLEs preceded by PSs (Fig. $2 A ; n=50$ ).

Intracellular recordings from both superficial and deep principal EC cells $(n=21$ in BMI; rmp: $-58.3 \pm 7.3 \mathrm{mV} ; n=22$ in 4AP; rmp: $-73.9 \pm 1.6 \mathrm{mV}$; mean \pm SD) demonstrated that PSs correlated with an inhibitory potential in 33 neurons ( 35 seizures, 16 in BMI and 19 in 4AP; see Fig. 4A), a few-millivolt depolarization without firing in 6 neurons ( 4 in BMI and 2 in 4AP; see Fig. $4 A$ ), and a burst of action potentials in 4 principal cells ( 3 in BMI and 1 in $4 \mathrm{AP}$; see Fig. $4 A$ ). Intracellular activity showed a PSassociated putative IPSP (Fig. $2 \mathrm{~A}, \mathrm{~B}$ ) peaking at $-65.4 \pm 7.4 \mathrm{mV}$ (mean $\pm \mathrm{SD}$ ) during $4 \mathrm{AP}$ application and $-66.8 \pm 7.3 \mathrm{mV}$ during BMI application (Fig. 3). In all $(n=20)$ but three principal neurons, ISs that occurred at the end or between two SLEs correlated at the intracellular level with a spike or a burst of action potentials superimposed to a paroxysmal depolarizing shift (Fig. 3). These data demonstrate that, in the same principal neuron, spike events occurring just before (pre-ictal) and after a SLE (between two SLEs) were correlated with inhibitory and depolarizing potentials, respectively. The small depolarizing hump seldom recorded before the IPSPs (Fig. 2Bb) was interpreted either as an excitatory PSP or as a passive membrane potential oscillation.

The mean duration of the PSs was $382.2 \pm 139.7 \mathrm{~ms}$ in BMI and $184.8 \pm 19.7 \mathrm{~ms}$ in $4 \mathrm{AP}($ mean $\pm \mathrm{SD})$. We analyzed the firing rate before and after 80 PSs in 13 principal neurons (6 during $\mathrm{BMI}$ and 7 in 4AP) with background firing activity before seizure initiation. The averaged firing frequency in the $380 \mathrm{~ms}$ (in BMI) and $180 \mathrm{~ms}$ (in 4AP) before a PS was $11.5 \pm 7.1 \mathrm{~Hz}$. This firing frequency measured before a PS decreased to $0.6 \pm 0.8 \mathrm{~Hz}$ during the PSs (Fig. $4 B$, left; mean $\pm \mathrm{SD}$ ).

Putative interneurons identified by neurophysiological criteria (spike rate, firing accommodation, and response to LOT stimulation; Gnatkovsky et al., 2007) recorded after application of BMI and $4 \mathrm{AP}$ ( $n=3$ and $n=1$, respectively) generated bursting activity during the PSs (Figs. 2D, 4A). In these 4 putative interneurons, the background firing rate was $13.4 \pm 21.8 \mathrm{~Hz}$ and increased to $166.2 \pm 78.4 \mathrm{~Hz}$ during 14 PSs (Fig. 4B, right; mean \pm SD). We analyzed separately the correlation between the amplitude of individual PSs and the firing frequency of the interneurons and found a high correlation between these two parameters $\left(r^{2}>0.8\right.$ in all experiments; Fig. 5). Altogether, these data suggest that, in both 4AP- and BMI-induced epileptogenesis, PSs are associated with IPSPs recorded in principal neurons and generated by spontaneous, burst-like firing activity in interneurons.

\section{Discussion}

We analyzed population spikes generated in the EC of the isolated guinea pig brain by two different epileptogenic compounds: the $\mathrm{GABA}_{\mathrm{A}}$ receptor antagonist BMI and the $\mathrm{K}^{+}$channel blocker 4AP. Regardless of their different mechanisms of action, both drugs induced similar ictal patterns in the temporal/limbic region (Librizzi and de Curtis, 2003; Carriero et al., 2010; Boido et al., 2014) that resemble seizures recorded with intracerebral electrodes in patients with mesial temporal lobe epilepsy (TLE; Engel, 
A

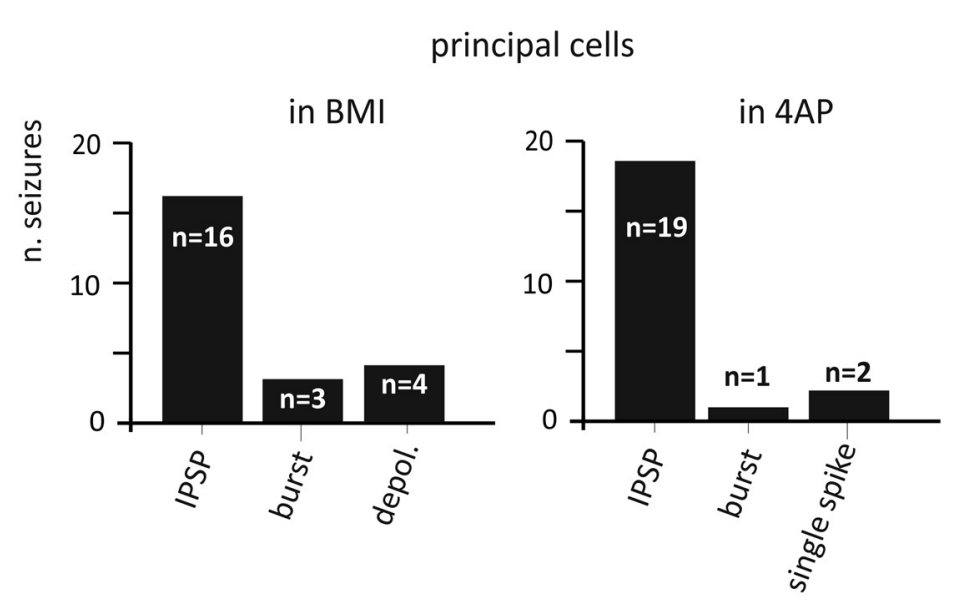

interneurons

\author{
in $\mathrm{BMI}$ or $4 \mathrm{AP}$
}

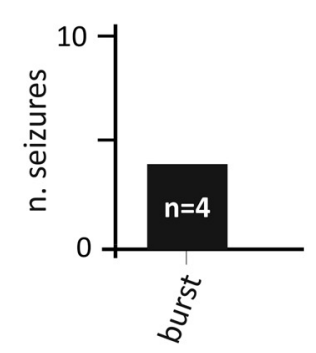

B principal cells interneurons
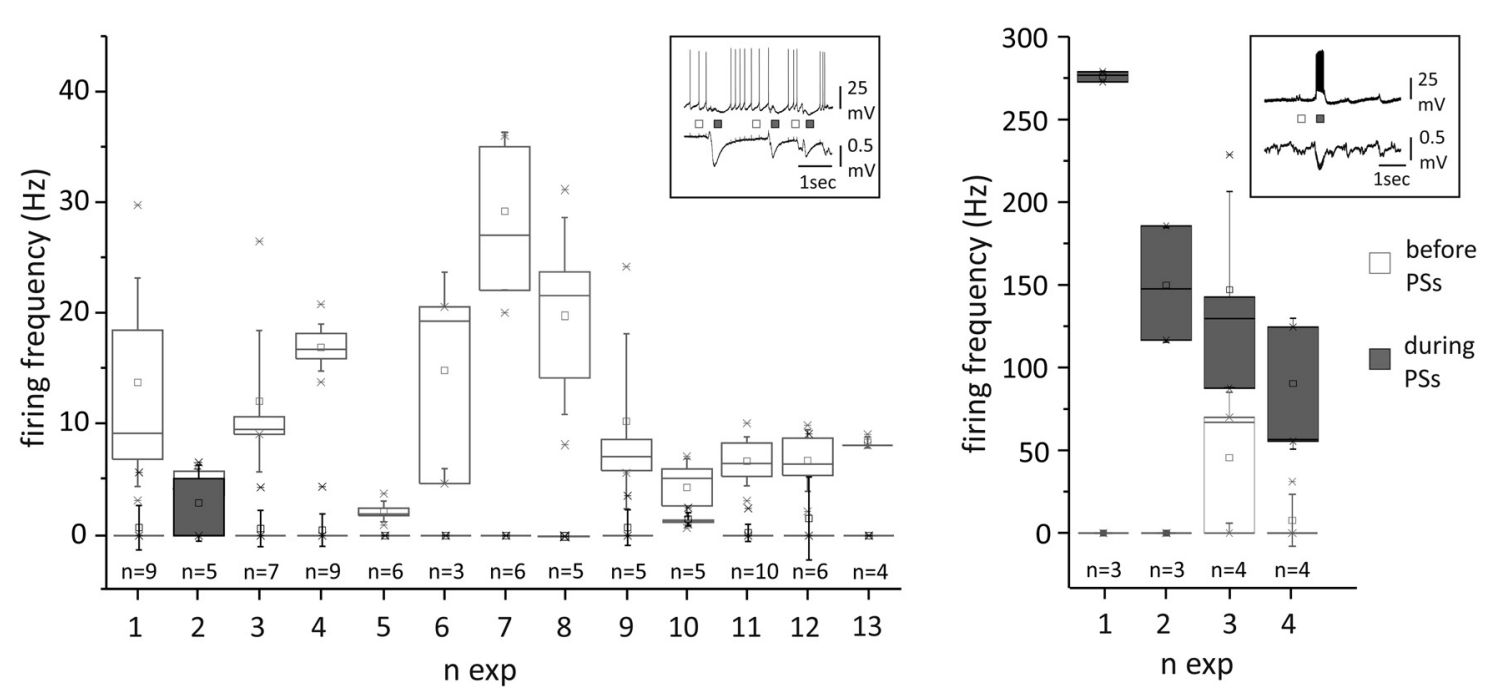

Figure 4. A, Quantification of the different intracellular correlates of principal cells (left) and interneurons (right) during PSs induced by arterial application of BMI or 4AP. B, Box plots showing the firing frequencies of principal cells (left) and interneurons (right) before and during PSs, represented by white and gray boxes, respectively. The box ranges indicate the 25 th and 75 th percentile and the whiskers the SD values. Typical intracellular and extracellular activities recorded during PSs in principal cells and interneurons are illustrated in the top inserts. Note that, with the exception of cells 2 and 10, firing rate of principal neurons during PS is decreased to zero.

1990; Wendling et al., 2012) and in animal models of mesial TLE (Bragin et al., 1999; Carriero et al., 2012). SLEs induced by arterially applied $\mathrm{BMI}$ in the intact brain in vitro initiates with fast activity in the $\beta$ range $(20-30 \mathrm{~Hz})$, followed by irregular spiking and periodic bursting (Uva et al., 2005; Gnatkovsky et al., 2008; Trombin et al., 2011) restricted to the hippocampal and parahippocampal areas (Uva et al., 2005) with a different involvement of subregions during SLE phases (Boido et al., 2014). A similar sequence of ictal events was observed in the isolated guinea pig brain perfused with $4 \mathrm{AP}$ via the arterial system (Carriero et al., 2010).

As for human mesial TLE (Bragin et al., 2005; Wendling et al., 2005), PSs initiate both 4AP- and BMI-induced SLEs. These PSs are legitimate ictal events because they were observed exclusively in coincidence with seizure onset. We demonstrate in two different models of SLE that PSs are sustained by network mechanisms different from ISs recorded in the same regions. In the large majority of EC neurons after both BMI and 4AP application, PSs correlated with inhibitory potentials and with the blockade of firing in principal neurons. Because pharmacological manipula- tions during the few tens of seconds that precede a randomly occurring SLE is not feasible, to understand the nature of PSs, we compared the PS-associated potential with the IPSPs evoked in the same neuron by stimulation of the LOT before the application of the proconvulsive drug. We previously demonstrated that LOT stimulation induces a polisynaptic response in layer II and III neurons of the EC that is mediated by a feedforward GABAergic IPSP (Gnatkovsky and de Curtis, 2006). The reversal potential of LOT-induced IPSP in EC neurons was $\sim-67 \mathrm{mV}$ and correlated with the maximal hyperpolarizing deflection observed in EC neurons during PSs. These data are confirmed in neurons in which membrane potential was modified by intracellular current injection during PSs and SLE occurrence. The presence of an inhibitory hyperpolarizing potential during the PS was further confirmed by the demonstration that neuronal firing was abolished in 33 of 43 principal neurons during both in BMI- and 4AP-induced PSs. Moreover, putative interneurons identified by neurophysiological criteria (Gnatkovsky et al., 2007) recorded during the PSs at the onset of BMI- and 4AP-induced SLE showed a bursting discharge, suggesting that IPSPs recorded in principal 


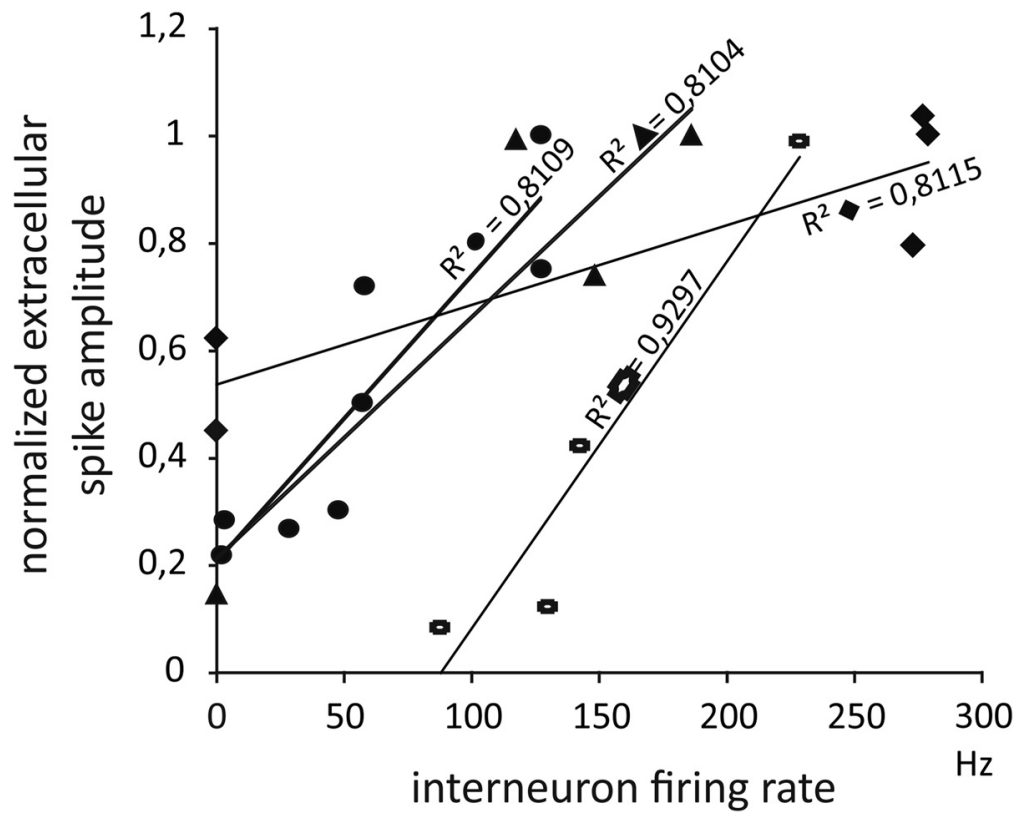

Figure 5. Relationship between the firing rate of the four putative interneurons and the amplitudes of extracellular PSs induced by BMI or 4AP administration. Four to eight PSs of different amplitudes were analyzed for each interneuron represented by different symbols. Regression lines and the corresponding correlation coefficients $\left(r^{2}\right)$ values are reported for each interneuron.

of the phenomenon (i.e., activation of GABAergic cells has an inhibitory function) and do not consider the possibility that increased interneuronal network activity just ahead of a focal seizure could be directly responsible for seizure precipitation.

The role of GABAergic networks in promoting SLEs in EC has been proposed by experiments conducted on hippocampalentorhinal slices (Avoli, 1996; Lopantsev and Avoli, 1998 Fujiwara-Tsukamoto et al., 2006; Köhling et al., 2000; Ziburkus et al., 2006; see for review de Curtis and Gnatkovsky, 2009; Fujiwara-Tsukamoto et al., 2010; Avoli and de Curtis, 2011). In the rat and human neocortex perfused with $4 \mathrm{AP}$, ictal discharges are initiated by $\mathrm{GABA}_{\mathrm{A}}$ receptor activation (Avoli et al., 1996; D'Antuono et al., 2004). In rat brain slices exposed to $4 \mathrm{AP}$ or $0 \mathrm{~mm} \mathrm{Mg}^{2+}$, $\mathrm{GABA}_{\mathrm{A}}$-mediated spikes or oscillations anticipating the ictal discharge were recorded and the interference with $\mathrm{GABA}_{\mathrm{A}}$ transmission determined their abolition together with ictal discharge suppression

neurons are due to increased activity of local circuit inhibitory cells. These findings acquire a particular significance for the understanding of human focal epilepsy in the light of the recent demonstration of a reduced unit activity at seizure onset in humans (Truccolo et al., 2011; Schevon et al., 2012) and in epilepsy animal models (Grasse et al., 2013).

In rat slices bathed in $4 \mathrm{AP}$, population spikes sustained exclusively by GABAergic networks have been demonstrated in hippocampus (Avoli, 1990; Perreault and Avoli, 1992) and EC (Lopantsev and Avoli, 1998; Avoli and de Curtis, 2011). Similarly, when glutamatergic transmission was blocked during arterial administration of $4 \mathrm{AP}$ in the isolated guinea pig brain, $\mathrm{GABA}_{\mathrm{A}}-$ mediated synchronous potentials were uncovered (Uva et al., 2009). These GABAergic spikes correlated with membrane hyperpolarization in principal EC neurons and were blocked by BMI. In these conditions of blockade of excitatory transmission, GABAergic spikes were not sufficient to generate SLEs (Uva et al., 2009). Similar network events could subtend PSs.

We hypothesize that 4AP generates GABAergic PSs by enhancing spontaneous interactions predominantly within inhibitory networks. 4AP blockade of repolarizing potassium conductance may elongate action potential repolarization in presynaptic terminals, thus reinforcing synaptic release at inhibitory synapses. GABAergic spikes during the BMI incomplete impairment of GABAa receptor function (see Fig. 1 in Gnatkovsky et al., 2008) could be due to a reduction of interneuron-to-interneuron inhibition. These two hypothetical mechanisms could promote inhibitory network synchronization underlying PSs.

Enhanced inhibitory neuron activity preceding SLE onset have been also documented in rat and mouse cortical brain slices (Trevelyan et al., 2006; Ziburkus et al., 2006; Cammarota et al., 2013). Such inhibitory network activation has been interpreted as a hyperpolarizing wave of inhibition that entrains interneuronal networks to confine the spreading of ictal activity. In another study, it has been proposed that ictal activity occurs when excitatory inputs overcome the inhibitory drive (Derchansky et al., 2008). All of these studies present a conventional interpretation
(Avoli, 1996; Köhling et al., 2000). The progression of a seizure from the initial enhanced inhibitory network activity is presumably mediated either by an increase in extracellular $\mathrm{K}^{+}$associated with interneuronal activity (Avoli, 1996; D'Antuono et al., 2004; Trombin et al., 2011) or by an excitatory rebound caused by the synchronous inhibition (Cobb et al., 1995; Wendling et al., 2002).

Because arterial application of both BMI and 4AP did not induce sustained ISs in the limbic region, we studied ISs induced by local intracortical application of BMI. As for the olfactory cortex of the isolated guinea pig brain (de Curtis et al., 1994; de Curtis et al., 1998a; de Curtis et al., 1999), this procedure promoted periodic interictal spiking in the EC, but never generated SLEs. It is well known that the direct local injection of BMI (and other convulsants) into the cortex in vivo generates large interictal events that periodically recur, but fails to induce seizures (Prince and Wilder, 1967; Ma et al., 2004). Previous findings obtained in the olfactory cortex of the isolated guinea pig brain strongly suggested that BMI- or picrotoxin-induced ISs are generated by a transient and brief synchronization of excitatory circuits, followed by synchronization of inhibition possibly mediated by intrinsic $\mathrm{K}^{+}$conductances and $\mathrm{GABA}_{\mathrm{B}}$ receptor activation that prevents seizure precipitation (de Curtis et al., 1998a). The intracellular activity pattern associated to ISs in the piriform cortex (de Curtis et al., 1998a; de Curtis et al., 1999) was confirmed for the EC in the present report. ISs induced by local BMI application in the EC corresponded to a long-lasting membrane depolarization coupled to the discharge of a burst of action potentials. We demonstrated that these ISs are sustained by glutamatergic networks because they were blocked by the non-NMDA glutamate receptor blocker DNQX (see also de Curtis et al., 1999). Local DNQX was associated with an increase in the amplitude of ISs recorded at a distance from its application. This could be due to the natural evolution of ISs that progressively become larger to reach a plateau amplitude; this increase is blocked at the site of DNQX action. Alternatively, DNQX could block recurrent excitation on remotely acting interneurons, thus reducing inhibition in principal cells out of the area of DNQX influence. 
We confirmed that ISs induced by local drug applications and ISs observed between two seizures in our experimental conditions correlate with a PDS (Ayala et al., 1973; Traub and Wong, 1982) mediated by activation of glutamate receptors, as was demonstrated previously in slices of hippocampus (Stanton et al., 1987), neocortex (Hablitz, 1984; Hwa and Avoli, 1991), piriform cortex (Hoffman and Haberly, 1991; Forti et al., 1997), and EC (Jones and Heinemann, 1988).

In conclusion, local activation of the EC with proconvulsive drugs abolishes GABAergic transmission and generates PDSassociated glutamatergic ISs that recur but do not evolve into seizure-like activity. Conversely, brief arterial administration of $\mathrm{BMI}$ or 4AP induces a strong activation and synchronization of GABAergic circuits that generate PSs consistently developing into SLEs. These results support the concept that GABAergic circuit synchronization plays a pivotal role in the initiation of focal epileptic seizures in the entorhinal cortex. Our findings support the novel concept that synchronization of inhibitory networks is associated with and could be causally linked to seizure initiation.

\section{References}

Avoli M (1990) Epileptiform discharges and a synchronous GABAergic potential induced by 4 -aminopyridine in the rat immature hippocampus. Neurosci Lett 117:93-98. CrossRef Medline

Avoli M (1996) GABA-mediated synchronous potentials and seizure generation. Epilepsia 37:1035-1042. CrossRef Medline

Avoli M, de Curtis M (2011) GABAergic synchronization in the limbic system and its role in the generation of epileptiform activity. Prog Neurobiol 95:104-132. CrossRef Medline

Avoli M, Barbarosie M, Lücke A, Nagao T, Lopantsev V, Köhling R (1996) Synchronous GABA-mediated potentials and epileptiform discharges in the rat limbic system in vitro. J Neurosci 16:3912-3924. Medline

Avoli M, D’Antuono M, Louvel J, Köhling R, Biagini G, Pumain R, D'Arcangelo G, Tancredi V (2002) Network and pharmacological mechanisms leading to epileptiform synchronization in the limbic system in vitro. Prog Neurobiol 68:167-207. CrossRef Medline

Ayala GF, Dichter M, Gumnit RJ, Matsumoto H, Spencer WA (1973) Genesis of epilectic interictal spikes. New knowledge of cortical feedback system suggest a neurophysiological explanation of brief paroxysms. Brain Res 52:1-17. CrossRef Medline

Biella G, de Curtis M (2000) Olfactory inputs activate the medial entorhinal cortex via the hippocampus. J Neurophysiol 83:1924-1931. Medline

Boido D, Jesuthasan N, de Curtis M, Uva L (2014) Network dynamics during the progression of seizure-like events in the hippocampal-parahippocampal regions. Cereb Cortex 24:163-173. CrossRef Medline

Bragin A, Engel J Jr, Wilson CL, Vizentin E, Mathern GW (1999) Electrophysiologic analysis of a chronic seizure model after unilateral hippocampal KA injection. Epilepsia 40:1210-1221. CrossRef Medline

Bragin A, Wilson CL, Fields T, Fried I, Engel J Jr (2005) Analysis of seizure onset on the basis of wideband EEG recordings. Epilepsia 46:59-63. CrossRef Medline

Cammarota M, Losi G, Chiavegato A, Zonta M, Carmignoto G (2013) Fast spiking interneuron control of seizure propagation in a cortical slice model of focal epilepsy. J Physiol 591:807-822. CrossRef Medline

Carriero G, Uva L, Gnatkovsky V, Avoli M, de Curtis M (2010) Independent epileptiform discharge patterns in the olfactory and limbic areas of the in vitro isolated Guinea pig brain during 4 -aminopyridine treatment. J Neurophysiol 103:2728-2736. CrossRef Medline

Carriero G, Arcieri S, Cattalini A, Corsi L, Gnatkovsky V, de Curtis M (2012) A guinea pig model of mesial temporal lobe epilepsy following nonconvulsive status epilepticus induced by unilateral intrahippocampal injection of kainic acid. Epilepsia 53:1917-1927. CrossRef Medline

Cobb SR, Buhl EH, Halasy K, Paulsen O, Somogyi P (1995) Synchronization of neuronal activity in hippocampus by individual GABAergic interneurons. Nature 378:75-78. CrossRef Medline

D’Antuono M, Louvel J, Köhling R, Mattia D, Bernasconi A, Olivier A, Turak B, Devaux A, Pumain R, Avoli M (2004) GABAA receptor-dependent synchronization leads to ictogenesis in the human dysplastic cortex. Brain 127:1626-1640. CrossRef Medline de Curtis M, Avanzini G (2001) Interictal spikes in focal epileptogenesis. Prog Neurobiol 63:541-567. CrossRef Medline

de Curtis M, Gnatkovsky V (2009) Reevaluating the mechanisms of focal ictogenesis: The role of low-voltage fast activity. Epilepsia 50:2514-2525. CrossRef Medline

de Curtis M, Paré D, Llinás RR (1991) The electrophysiology of the olfactory-hippocampal circuit in the isolated and perfused adult mammalian brain in vitro. Hippocampus 1:341-354. CrossRef Medline

de Curtis M, Biella G, Forti M, Panzica F (1994) Multifocal spontaneous epileptic activity induced by restricted bicuculline ejection in the piriform cortex of the isolated guinea pig brain. J Neurophysiol 71:2463-2476. Medline

de Curtis M, Manfridi A, Biella G (1998a) Activity-dependent pH shifts and periodic recurrence of spontaneous interictal spikes in a model of focal epileptogenesis. J Neurosci 18:7543-7551. Medline

de Curtis M, Biella G, Buccellati C, Folco G (1998b) Simultaneous investigation of the neuronal and vascular compartments in the guinea pig brain isolated in vitro. Brain Res Brain Res Protoc 3:221-228. CrossRef Medline

de Curtis M, Radici C, Forti M (1999) Cellular mechanisms underlying spontaneous interictal spikes in an acute model of focal cortical epileptogenesis. Neuroscience 88:107-117. CrossRef Medline

Derchansky M, Jahromi SS, Mamani M, Shin DS, Sik A, Carlen PL (2008) Transition to seizures in the isolated immature mouse hippocampus: a switch from dominant phasic inhibition to dominant phasic excitation. J Physiol 586:477-494. Medline

Dickson CT, Alonso A (1997) Muscarinic induction of synchronous population activity in the entorhinal cortex. J Neurosci 17:6729-6744. Medline

Engel J Jr (1990) The Hans Berger lecture. Functional explorations of the human epileptic brain and their therapeutic implications. Electroencephalogr Clin Neurophysiol 76:296-316. CrossRef Medline

Forti M, Biella G, Caccia S, de Curtis M (1997) Persistent excitability changes in the piriform cortex of the isolated guinea pig brain after transient exposure to bicuculline. Eur J Neurosci 9:435-451. CrossRef Medline

Fujiwara-Tsukamoto Y, Isomura Y, Takada M (2006) Comparable GABAergic mechanisms of hippocampal seizurelike activity in posttetanic and low-Mg2 + conditions. J Neurophysiol 95:2013-2019. CrossRef Medline

Fujiwara-Tsukamoto Y, Isomura Y, Imanishi M, Ninomiya T, Tsukada M, Yanagawa Y, Fukai T, Takada M (2010) Prototypic seizure activity driven by mature hippocampal fast-spiking interneurons. J Neurosci 30: 13679-13689. CrossRef Medline

Gnatkovsky V, de Curtis M (2006) Hippocampus-mediated activation of superficial and deep layer neurons in the medial entorhinal cortex of the isolated guinea pig brain. J Neurosci 26:873-881. CrossRef Medline

Gnatkovsky V, Wendling F, de Curtis M (2007) Cellular correlates of spontaneous periodic events in the medial entorhinal cortex of the in vitro isolated guinea pig brain. Eur J Neurosci 26:302-311. CrossRef Medline

Gnatkovsky V, Librizzi L, Trombin F, de Curtis M (2008) Fast activity at seizure onset is mediated by inhibitory circuits in the entorhinal cortex in vitro. Ann Neurol 64:674-686. CrossRef Medline

Grasse DW, Karunakaran S, Moxon KA (2013) Neuronal synchrony and the transition to spontaneous seizures. Exp Neurol 248:72-84. CrossRef Medline

Hablitz JJ (1984) Picrotoxin-induced epileptiform activity in hippocampus: role of endogenous versus synaptic factors. J Neurophysiol 51:1011-1027. Medline

Hoffman WH, Haberly LB (1991) Bursting-induced epileptiform EPSPs in slices of piriform cortex are generated by deep cells. J Neurosci 11:20212031. Medline

Huberfeld G, Wittner L, Clemenceau S, Baulac M, Kaila K, Miles R, Rivera C (2007) Perturbed chloride homeostasis and GABAergic signaling in human temporal lobe epilepsy. J Neurosci 27:9866-9873. CrossRef Medline

Hwa GG, Avoli M (1991) The involvement of excitatory amino acids in neocortical epileptogenesis: NMDA and non-NMDA receptors. Exp Brain Res 86:248-256. Medline

Jones RS, Heinemann U (1988) Synaptic and intrinsic responses of medial entorhinal cortical cells in normal and magnesium-free medium "in vitro." J Neurophysiol 59:1476-1496. Medline

Köhling R, Vreugdenhil M, Bracci E, Jefferys JG (2000) Ictal epileptiform activity is facilitated by hippocampal $\mathrm{GABA}_{\mathrm{A}}$ receptor-mediated oscillations. J Neurosci 20:6820-6829. Medline 
Lasztóczi B, Nyitrai G, Héja L, Kardos J (2009) Synchronization of GABAergic inputs to CA3 pyramidal cells precedes seizure-like event onset in juvenile rat hippocampal slices. J Neurophysiol 102:2538-2553. CrossRef Medline

Librizzi L, de Curtis M (2003) Epileptiform ictal discharges are prevented by periodic interictal spiking in the olfactory cortex. Ann Neurol 53:382389. CrossRef Medline

Lopantsev V, Avoli M (1998) Participation of GABAA-mediated inhibition in ictallike discharges in the rat entorhinal cortex. J Neurophysiol 79:352360. Medline

Ma HT, Wu CH, Wu JY (2004) Initiation of spontaneous epileptiform events in the rat neocortex in vivo. J Neurophysiol 91:934-945. Medline

Matsumoto H, Ajmone-Marsan C (1964) Cortical cellular phenomena in experimental epilepsy: interictal manifestations. Exp Neurol 9:286-304. CrossRef Medline

Michelson HB, Wong RK (1991) Excitatory synaptic responses mediated by $\mathrm{GABA}_{\mathrm{A}}$ receptors in the hippocampus. Science 253:1420-1423. CrossRef Medline

Mühlethaler M, de Curtis M, Walton K, Llinás R (1993) The isolated and perfused brain of the guinea pig in vitro. Eur J Neurosci 5:915-926. CrossRef Medline

Perreault P, Avoli M (1992) 4-aminopyridine-induced epileptiform activity and a GABA-mediated long-lasting depolarization in the rat hippocampus. J Neurosci 12:104-115. Medline

Prince DA, Wilder BJ (1967) Control mechanisms in cortical epileptogenic foci. "Surround" inhibition. Arch Neurol 16:194-202. CrossRef Medline

Schevon CA, Weiss SA, McKhann G Jr, Goodman RR, Yuste R, Emerson RG, Trevelyan AJ (2012) Evidence of an inhibitory restraint of seizure activity in humans. Nat Commun 3:1060. CrossRef Medline

Stanton PK, Jones RS, Mody I, Heinemann U (1987) Epileptiform activity induced by lowering extracellular magnesium in combined hippocamaplentorhinal cortex slices: modification by receptors for norepinephrine and N-methyl-D-aspartate. Epilepsy Res 1:53-62. CrossRef Medline

Traub RD, Wong RK (1982) Cellular mechanism of neuronal synchronization in epilepsy. Science 216:745-747. CrossRef Medline

Trevelyan AJ, Sussillo D, Watson BO, Yuste R (2006) Modular propagation of epileptiform activity: evidence for an inhibitory veto in neocortex. J Neurosci 26:12447-12455. CrossRef Medline
Trombin F, Gnatkovsky V, de Curtis M (2011) Changes In Action Potential Features During Focal Seizure Discharges In The Entorhinal Cortex Of The In Vitro Isolated Guinea Pig Brain. J Neurophysiol 106:1411-1423. CrossRef Medline

Truccolo W, Donoghue JA, Hochberg LR, Eskandar EN, Madsen JR, Anderson WS, Brown EN, Halgren E, Cash SS (2011) Single-neuron dynamics in human focal epilepsy. Nat Neurosci 14:635-641. CrossRef Medline

Uusisaari M, Smirnov S, Voipio J, Kaila K (2002) Spontaneous epileptiform activity mediated by $\mathrm{GABA}(\mathrm{A})$ receptors and gap junctions in the rat hippocampal slice following long-term exposure to GABA(B) antagonists. Neuropharmacology 43:563-572. CrossRef Medline

Uva L, Librizzi L, Wendling F, de Curtis M (2005) Propagation dynamics of epileptiform activity acutely induced by bicuculline in the hippocampalparahippocampal region of the isolated Guinea pig brain. Epilepsia 46: 1914-1925. CrossRef Medline

Uva L, Avoli M, de Curtis M (2009) Synchronous GABA-receptordependent potentials in limbic areas of the in-vitro isolated adult guinea pig brain. Eur J Neurosci 29:911-920. CrossRef Medline

Wendling F, Bartolomei F, Bellanger JJ, Chauvel P (2002) Epileptic fast activity can be explained by a model of impaired GABAergic dendritic inhibition. Eur J Neurosci 15:1499-1508. CrossRef Medline

Wendling F, Hernandez A, Bellanger JJ, Chauvel P, Bartolomei F (2005) Interictal to ictal transition in human temporal lobe epilepsy: insights from a computational model of intracerebral EEG. J Clin Neurophysiol 22:343-356. Medline

Wendling F, Bartolomei F, Mina F, Huneau C, Benquet P (2012) Interictal spikes, fast ripples and seizures in partial epilepsies-combining multilevel computational models with experimental data. Eur J Neurosci 36: 2164-2177. CrossRef Medline

Wittner L, Huberfeld G, Clémenceau S, Eross L, Dezamis E, Entz L, Ulbert I, Baulac M, Freund TF, Maglóczky Z, Miles R (2009) The epileptic human hippocampal cornu ammonis 2 region generates spontaneous interictal-like activity in vitro. Brain 132:3032-3046. CrossRef Medline

Ziburkus J, Cressman JR, Barreto E, Schiff SJ (2006) Interneuron and pyramidal cell interplay during in vitro seizure-like events. J Neurophysiol 95:3948-3954. CrossRef Medline 